\title{
Can Dietary Fiber Intake Be Increased through Nutritional Education and through Subsidies on Selected Food Products?
}

\author{
Mark Christopher Senia $\odot$, Senarath Dharmasena, and \\ Oral Capps Jr.
}

\begin{abstract}
Consumers in the United States fall short of meeting the recommended guideline for dietary fiber intake. Using a quarterly panel of households from Nielsen for the years 2004 through 2014, we employ a Heckman two-step approach to estimate nine panel regressions concerning per person fiber intakes derived from various food categories to uncover the importance of prices as well as socioeconomic and demographic factors. Prices play a prominent role in the per person intake of dietary fiber derived from the respective food products considered. Households below poverty thresholds had lower intakes of fiber relative to households above poverty thresholds. Ethnicity, race, age of the household head, region, and the presence of children also had significant effects on dietary fiber derived from the respective food categories. A proposed 20 percent subsidy applied to fruits and vegetables would increase per person intake of fiber by 9.4 percent. Therefore, if one were to consider meeting the dietary fiber requirement only through the provision of a subsidy, a large subsidy applied to fruits and vegetables would be required. Therefore, given the complex nature of the various factors affecting the intake of dietary fiber, the feasibility of using subsidies alone to increase the intake of dietary fiber is called into question.
\end{abstract}

Keywords: Dietary fiber, Dietary Guidelines, fiber intake, Heckman two-step, Nielsen Homescan Panel, subsidy, USDA Panel Regression

JEL Classification: D12, I18

The Dietary Guidelines for Americans are the main source of dietary recommendations for health professionals and government agencies in the United States and are published roughly every five years. Dietary fiber is

Mark Christopher Senia, PhD, Texas A\&M University, Department of Agricultural Economics, College Station, Texas. Senarath Dharmasena, Instructional Assistant Professor, Associate of the Agribusiness, Food and Consumer Economics Research Center, Texas A\&M University, Department of Agricultural Economics, College Station, Texas. Oral Capps, Jr., Executive Professor and Regents Professor, Co-Director of the Agribusiness, Food and Consumer Economics Research Center, Texas A\&M University, Department of Agricultural Economics, College Station, Texas. Correspondence: Mark Christopher Senia 2124 TAMU Department of Agricultural Economics Texas A\&M University College Station, TX 77843-2124 USA mcsenia@ tamu.edu

Agricultural and Resource Economics Review 48/3 (December 2019) 448-472

(C) The Author(s) 2019. This is an Open Access article, distributed under the terms of the Creative

Commons Attribution licence (http://creativecommons.org/licenses/by/4.0/), which permits unrestricted re-use, distribution, and reproduction in any medium, provided the original work is 
considered a nutrient of public health concern because increasing the intake of fiber can reduce chronic disease risk (HHS and USDA 2015, 60). The 2015-2020 Dietary Guidelines for Americans recommend that individuals have an intake of 25 grams of dietary fiber per 2,000 kcal consumed per day (HHS and USDA 2015). Despite nudges from the government, consumers in the United States do not purchase enough foods high in dietary fiber to satisfy the recommendations posited by the dietary guidelines. The average daily per person dietary fiber intake in the United States was 16 grams per day in 2009-2010 (Hoy and Goldman 2010).

Dietary fiber provides a range of important health benefits, particularly in preventing heart disease and diabetes. Clinical research finds that the intake of dietary fiber from cereals and fruits are inversely associated with the risk of coronary heart disease (Pereira et al. 2004). Furthermore, increased intake of dietary fiber may reduce cardiovascular disease, stroke, hypertension, diabetes, obesity, and some gastrointestinal diseases (McKeown et al. 2002; Anderson et al. 2009). There may be an association between adults who eat more whole grains, particularly those high in dietary fiber, and a lower body weight relative to adults who eat fewer whole grains (USDA 2010).

The government can influence the diets of consumers in a number of ways. One option is to publish guidelines for a healthy diet formulated through recommendations from nutrition and dietary experts. The Dietary Guidelines for Americans serve in this capacity. These guidelines have been shown to lead to a decrease in intake of calories derived from consumption of nonalcoholic beverages (Dharmasena et al. 2011) as well as an increase in the demand for whole-grain products (Mancino and Kuchler 2012). It may then be expected that the guidelines can influence other areas of the diet such as increasing the intake of calcium, potassium, dietary fiber, and vitamin D. ${ }^{1}$

Another option available for the government is to influence the price of a product to bring about changes in consumption. For example, a 10 percent subsidy for low-income Americans was shown to increase consumption of fruits by 2.1-5.2 percent and vegetables by 2.1-4.9 percent (Dong and Lin 2009). A 20 percent subsidy on healthy dishes in a university cafeteria generated a 6 percent increase in the consumption of healthy foods and a 2 percent decline in the consumption of less-healthy foods (Michels et al. 2008).

The objective of this study is to contribute to the understanding of the factors influencing the intake of dietary fiber. This issue is important for food processors as well as government policy makers. We contribute to the literature by using a Heckman two-step approach to estimate panel regressions on per person fiber intake derived from nine categories of food products, namely: (1) bread, (2) pasta, (3) tortillas, (4) fresh fruit, (5) fresh

\footnotetext{
1 The 2015-2020 Dietary Guidelines for Americans define these nutrients as under-consumed and as nutrients of public health concern because low intakes are associated with health concerns (HHS and USDA, 2015, p. 60).
} 
vegetables and beans, (6) frozen fruit, (7) frozen vegetables and beans, (8) canned fruit, and (9) canned vegetables and beans. The panel regression is used to uncover socioeconomic and demographic factors concerning the per person intake of dietary fiber in the United States. The results are used to determine the effect on dietary fiber intake from different scenarios associated with a 20 percent drop in price due to a subsidy on canned, fresh, and frozen fruits and vegetables.

The empirical analysis is based on a quarterly panel of households participating in the Nielsen Homescan Panel for the calendar years 2004 through 2014. Information is collected on purchases from participating panelists on a quarterly basis along with socioeconomic and demographic information pertaining to each household.

The main findings are briefly summarized as follows. Those living below 130 percent and between 130 percent and 185 percent of the poverty level have significantly less fiber intake on a per person basis relative to those living above these poverty threshold levels. Regional effects in fiber intakes also were evident.

We find that the own-price elasticities with regard to fiber intake for all categories were less than one in absolute value. Hence, the derived demand for dietary fiber was inelastic. Estimates of the conditional own-price elasticities for fiber derived from fruit ranged from -0.25 for canned fruit to -0.53 for fresh fruit. Estimates of the conditional own-price elasticities for fiber derived from vegetables ranged from -0.52 for frozen vegetables to -0.97 for canned vegetables. The results also indicated that fiber derived from the various forms of vegetables and fruits were not substitutes for each other.

A 20 percent decrease in price to consumers due to a subsidy applied to all categories of fruits and vegetables would result in an increase in the average per person intake of fiber per day by 9.4 percent. Therefore, if one were to consider meeting the dietary fiber requirement only through the provision of a subsidy, a large subsidy applied to fruits and vegetables would be required. Thus, subsidies alone would not be feasible to entice consumers to meet the daily fiber intake guideline.

\section{Literature Review}

\section{Nutritional Contribution of Dietary Fiber}

The average per person U.S. dietary fiber intake of 16 grams per day in 20092010 (Hoy and Goldman 2010) falls far short of the average recommendation of 25 grams per day for a 2,000 kcal diet. From the U.S. food supply, 25 grams of dietary fiber per person per day is available (Economic Research Service 2015). The majority of this availability is from grains (35.1 percent), vegetables (22.7 percent), legumes, nuts, and soy (16.2 percent), and fruits (11.3 percent). 
Therefore, lack of availability is not the problem. By falling short of a sufficient intake of dietary fiber, Americans are not able to enjoy the range of important health benefits provided by this nutritional element. Most important are its possible associations with a reduction of heart disease and type 2 diabetes.

According to one clinical study, the intake of dietary fiber from cereals and fruits is inversely associated with the risk of coronary heart disease (Pereira et al. 2004). This reduction may be as high as a 40 percent lower risk of coronary heart disease (Rimm et al. 1996). A high intake of dietary fiber also is associated with a lower risk of metabolic syndrome, a set of medical conditions that increase the risk of developing heart disease and diabetes (McKeown et al. 2002).

Dietary fiber also appears to be an important component in lowering the risk of developing type 2 diabetes. A diet high in dietary fiber and lower in high-glycemic-index foods may be associated with a reduction in developing diabetes for men (Fung et al. 2002) and for women (Liu et al. 2000). More specifically, black women face a much higher incidence of type 2 diabetes and demonstrate the need for increasing dietary fiber intake (Krishnan et al. 2007).

Increased intake of dietary fiber also may reduce stroke, hypertension, obesity, and some gastrointestinal diseases (McKeown et al. 2002; Anderson et al. 2009). There is an association between adults who eat more whole grains, particularly those high in dietary fiber, and a lower body weight (USDA 2010). These important health benefits from dietary fiber intake make it a vital component of the U.S. diet.

\section{Economic Considerations of Dietary Fiber Consumption}

Current literature dealing solely with dietary fiber intake is limited. Miguel and Dong (2012) used a dynamic Tobit model that allows past purchase occasions to affect current purchase decisions for fiber using the 2009 Nielsen Homescan Panel. Participation in the Supplemental Nutrition Assistance Program for Women, Infants and Children (WIC program), one the of U.S. federal government's food and nutrition assistance programs, the age and presence of children between thirteen and seventeen, not being Hispanic, and the employment level of the female head did not significantly affect fiber intake. Additionally, the education level of the female head had a negative impact on fiber intake and coupon use had a positive effect. Fiber derived from fresh or frozen fruits and vegetables was not included in this analysis, and the sources of dietary fiber were not partitioned into separate food categories.

Much of the economic literature has focused on whole-grain products (a good source of dietary fiber) likely due to the U.S. Department of Agriculture (USDA) making specific intake recommendations in 2005. Mancino et al. (2008) found that the release of the 2005 Dietary Guidelines for Americans increased the availability and sales of whole-grain foods, with a large impact due to reformulation of existing products. Mancino and Kuchler (2012) estimated 
the demand for whole-grain bread to determine if the release of the 2005 Dietary Guidelines for Americans affected demand for whole grain. In this study, the release of the 2005 Dietary Guidelines was positively associated with an increase in consumption of whole-grain products even after accounting for price changes.

The government can attempt to make a desired food group more widely consumed by allowing consumers to pay less, otherwise known as subsidization. Dong and Lin (2009) estimated that a 10 percent subsidy would encourage low-income Americans to increase their consumption of fruits by 2.1-5.2 percent and vegetables by 2.1-4.9 percent. Lin, Yen, Dong, and Smallwood (2010) found that a 10 percent price subsidy on fruits and vegetables for Supplemental Nutritional Assistance Program (SNAP) recipients increased at-home consumption of vegetables by 6 percent and increased consumption of fruits by 11 percent.

Other literature has explored providing subsidies to SNAP participants. Certain SNAP participants were provided with a 30 percent incentive for purchases of targeted fruits and vegetables under the USDA Food and Nutrition Service Healthy Incentives Pilot (HIP). Klerman et al. (2014) found this incentive was able to close the gap between recommended and current intake of fruits and vegetables by about 20 percent. Wilde et al. (2016) found HIP had impacts beyond the target fruits and vegetables. The total selfreported fruit and vegetable spending was approximately five times larger than the impact on only the target fruits and vegetables. One possible explanation put forth was the impact that information and promotional efforts had on overall fruit and vegetable consumption. If subsidies or promotional efforts are not options, Klerman, Collings, and Olsho (2017) argue that a requirement for SNAP to only be used for certain healthy foods is preferable to banning SNAP from being used on unhealthy foods.

From this review of the literature, it is clear that only a limited amount of research has been conducted related to dietary fiber intake. Therefore, a more comprehensive study incorporating the intake of dietary fiber derived from various food types and the impact of socioeconomic and demographic factors is needed. This lack of information in the extant literature serves as the motivation for our study.

\section{Empirical Model and Estimation Procedure}

Generally speaking, not all households (or individuals) purchase all food types during the sampling period, resulting in zero expenditure levels (and quantities) reported for some foods under consideration (also known as the data censoring problem). The application of ordinary least squares (OLS) to estimate a regression with a censored dependent variable can result in biased estimates (Kennedy 2003). Dropping the observations with zero reported expenditures would result in sample selection bias. Therefore, to account for zero instances (or censored data) of fiber intake, we adopt a 
Heckman two-step sample selection procedure (Heckman 1979). To account for the panel nature of the data, a random effects panel model is used in the second step to estimate the demand for particular foods rich in dietary fiber. The households in the panel are likely to differ in culture, tastes, and other unobservable factors. Thus, it is reasonable to assume that the differences among them are randomly distributed.

The first stage involves the decision to purchase a food product. Let $Z_{i t}^{*}$ be a latent selection variable described by equation (1):

$$
z_{i t}^{*}=\boldsymbol{x}_{i t} \gamma+\varepsilon_{i t},
$$

where the latent selection variable is described as $j, y_{i j}$,

$$
z_{i t}=\left\{\begin{array}{ll}
z_{i t}^{*}=\boldsymbol{x}_{i t} \gamma_{i}+\varepsilon_{i t}, & \text { if } z_{i t}^{*}>0 \\
0, & \text { if } z_{i t}^{*} \leq 0
\end{array} .\right.
$$

for $i=1,2, \ldots, N, t=1,2, \ldots, T$. For equation (1), $\boldsymbol{x}_{i t}$ is the vector of explanatory variables for household $i$ (e.g., prices and demographics), $\gamma$ is the vector of coefficients to estimate, and $\varepsilon_{i t}$ are the error terms which are assumed to be identically and independently distributed (i.i.d). $\mathcal{N}\left(0, \sigma_{\mathrm{e}}^{2}\right)$. The decision to purchase a food product is modeled through the use of a probit model. The estimation of this model leads to an inverse Mills Ratio (IMR) (calculated as a ratio between the probability density function and cumulative distribution of probabilities derived from the standard normal distribution assumed in the probit model) that is included in the second stage regression to account for sample selection bias due to non-purchase events.

The second stage with panel-level random effects is described as:

$$
y_{i t k}^{*}=\boldsymbol{x}_{i t k} \beta_{i k}+\alpha_{i k} \lambda_{i t k}+v_{i k}+\varepsilon_{i t k},
$$

where $y_{i t k}^{*}$ denotes the amount of dietary fiber derived from food product $k$ for household $i$ in time period $t, \boldsymbol{x}_{i t k}$ is the vector of explanatory variables for household $i$ (e.g., prices and demographics) and product $k$ in time period $t, \lambda_{i t k}$ is the IMR, $\beta$ is the vector of coefficients to estimate for product $k, v_{i k}$ are the random effects which are independently and identically distributed (i.i.d.) $\mathcal{N}\left(0, \sigma_{\mathrm{v}}^{2}\right)$, and $\varepsilon_{i t k}$ are the error terms which are i.i.d. $\mathcal{N}\left(0, \sigma_{\mathrm{e}}^{2}\right)$ and independent of $v_{i k}$.

Given that regressors appear in both the first and second stage regressions, we employ the calculation of Saha, Capps, and Byrne (1997) to derive the appropriate marginal effects. This calculation takes the form:

$$
\widehat{M E_{j k}}=\widehat{\beta_{j k}}-\widehat{\alpha_{k}} \widehat{\gamma}_{j}\left\{\left(\boldsymbol{x}_{j k} \widehat{\gamma_{j k}}\right) \widehat{\lambda_{j k}}+\widehat{\lambda_{j k}^{2}}\right\},
$$

where $\widehat{\beta_{j k}}$ is the estimated coefficient for the $j$ th explanatory variable for 
product $k$ from the second stage, $\widehat{\alpha_{k}}$ is the estimated parameter associated with the IMR, $\widehat{\gamma_{j k}}$ is the estimated coefficient for the $j t h$ explanatory variable from the first stage, $\boldsymbol{x}_{j k} \widehat{\gamma_{j k}}$ is the predicted value from the first stage for product $k$, and $\widehat{\lambda_{j k}}$ is the estimated IMR from the first stage for the product $k$. We estimate the model parameters, standard errors, and marginal effects using Stata 14 (STATA, 2015). ${ }^{2}$

The panel-level random effects models for the respective food products represented by (3) are estimated independently as separate equations for each of the nine aforementioned food categories. We chose not to use a demand system approach largely because the theorized restrictions of homogeneity and symmetry are often rejected when tested empirically. As well, an unconstrained approach may be more suitable because of the numerous zero expenditure observations. Finally, because the pairwise correlations of the error terms between the single equation models are negligible, a systems approach is not warranted.

In order to investigate the effect of a proposed subsidy, we begin by finding a baseline intake of dietary fiber as an average of the last four quarters of the data for each household. Then for each dietary fiber intake category, we increase or decrease this baseline amount based on the corresponding estimated conditional own-price and cross-price elasticities. This procedure assumes that any change in fiber intake will be met by a change in supply at the current price. This assumption is reasonable since the current intake of dietary fiber is 16 grams per person per day and the current U.S. food supply provides around 25 grams per person per day for a 2,000 kcal diet (Hoy and Goldman, 2010; Economic Research Service 2015). This situation corresponds to a relatively inelastic demand curve and a perfectly elastic supply curve, which means a 100 percent pass through of the price reduction to consumers. Different scenarios are analyzed for the 20 percent reduction in price due to the subsidy: (1) all fruit and vegetables, (2) canned fruit and vegetables only, and (3) fresh fruit and vegetables only.

\section{Data}

Data are obtained from the Nielsen Homescan Panel (Nielsen 2018) over the period 2004 through $2014 .^{3}$ We create a quarterly panel of households for the years 2004 through 2014 (44 quarters) consisting of 9,896 households

\footnotetext{
2 The first stage is estimated using the probit command and the second stage is estimated using the xtreg command with conventional standard errors.

3 Calculated (or derived) based on data from The Nielsen Company (US), LLC and marketing database provided by the Kilts Center for Marketing Data Center at The University of Chicago Booth School of Business. The conclusions drawn from the Nielsen data are those of the researchers and do not reflect the views of Nielsen. Nielsen is not responsible for, had no role in, and was not involved in analyzing and preparing the results reported herein.
} 
across the United States totaling 435,424 observations. ${ }^{4}$ In this sample, 90 percent of households report a positive intake of dietary fiber based on the food categories selected for analysis. Each participating household is given a scanner to read Universal Product Codes (UPCs) of products purchased at stores. Nielsen matches the scanned UPC with product characteristics in their database. The household is also asked to enter quantity, expenditure, and any coupon information about the products purchased.

The quantity of each food product, the fiber quantities derived from these products, and demographic characteristics of the household are obtained. The food products selected for study are bread, pasta, tortillas, fresh fruit, fresh vegetables and beans, frozen fruit, frozen vegetables and beans, canned fruit, canned vegetables and beans. Each product in the dataset is recorded based on its associated Universal Product Code (UPC) as well as an abbreviated product description. For each product, an estimate is made of the fiber content by utilizing a keyword search over the abbreviated product descriptions. $^{5}$

We only include products with a UPC and do not include information about random weight produce. We are not able to adequately estimate the dietary content for a broad category of random weight fruit or vegetable purchases. Thus, it was necessary to exclude random weight items from our analysis. We do not believe the lack of random weight purchases will have a major effect on our results. This issue is not unique when analyzing Nielsen data. Dettmann and Dimitri (2009) found that random weight vegetable purchases comprised 11 percent of their sample when justifying dropping random weight items from their analysis. Piernas et al. (2013) also dropped random weight products from their analysis and found it justified because packaged foods constitute a higher contribution to total energy intake. We believe that the Nielsen data are a sufficiently strong source of fiber purchase information which is recorded and is better than dietary recall data.

We were able to identify around 154,000 products across the aforementioned nine food categories. Subsequently, the fiber content for each category is summed to create the total fiber intake for the household in that quarter for each of the nine categories. This total for each category is then divided by the number of members of the household to create an approximation of daily dietary fiber intake per person. ${ }^{6}$ Dividing by household size to derive the intra-household allocations is not unique. For example, this approach is taken in Dharmasena, Capps, and Clauson (2011) and Zhen et al. (2013).

\footnotetext{
4 The use of this panel may introduce sample selection bias. We assume that the magnitude of this sample selection bias is negligible.

5 The details on the assumptions for the UPC abbreviations and the assumed associated reference numbers to the USDA National Nutrient Database (NDB) for Standard Reference can be obtained from the authors upon request.

6 It is not a guarantee that the total amount of food purchased will be consumed. Thus, this number represents the total maximum possible intake of dietary fiber.
} 
Summary statistics of the dependent variables are listed in Table 1. The means presented are conditional on a positive intake in that category. The largest sources of fiber based on the conditional means are bread, canned vegetables, and fresh vegetables. It is important to note the large number of zero observations for some of the categories. Across all food products, 8,864 of the 9,964 households report a non-zero per person fiber intake.

In Figure 1, a histogram for the daily fiber intake per person is shown. The average daily fiber intake per person of our sample is 4.38 grams. This level falls far short of the USDA target of 25 grams per person per day for a 2,000 kcal diet. The majority of our sample is not meeting the USDA guidelines. The USDA (2010, pg. 46) estimates the typical American diet provides 40 percent of needed fiber. Our sample average shows participants meeting slightly less than 20 percent of the recommended target of 25 grams per person. King, Mainous, and Lambourne (2012), using data from the National Health and Nutrition Examination Survey (NHANES), found that mean dietary fiber intakes over the period 1999 to 2008 were in the interval of 15.5 grams/day to 16.1 grams/day. Recall that the dietary fiber intake in our study is derived from only nine food products purchased for at-home consumption, and random weight produce purchases are excluded from this analysis. As such, other possible dietary fiber sources are not included in this research. ${ }^{7}$

For the explanatory variables, unit values (proxy for prices) are calculated by taking the total expenditure in a category and dividing by the total weight (grams) purchased for that category. We observe no unit value or price for the transactions with zero quantities and hence zero expenditures (due to censored nature of these observations). Missing prices are imputed using an auxiliary regression of quantity purchased based on household income, household size, location, and time variables. The variable for income controls for different levels of quality, while the other variables account for price differences associated with regional differences, demographic variability, and time effects. The use of such imputed prices in the regression model also helps deal with potential endogeneity in the price variable. This approach is not without precedent and is standard procedure in the price imputation literature (Capps et al. 1994; Alviola and Capps 2010; Kyureghian, Capps, and Nayga 2011; Dharmasena and Capps 2014). ${ }^{8}$ In Table 2, we present summary statistics for observed prices and imputed prices for each of the product categories. The table shows that the means of the imputed prices are close to

\footnotetext{
7 Given these data limitations, seeking a realistic estimate of this gap between current intake and recommendations is not within the purview of our research.

8 We acknowledge that unit values encumber both quality variation and price variation. As stated in Alviola and Capps (2010), because unit values may reflect quality differences, estimated income and price elasticities may be biased. However, we believe that the commodities involved in this study are sufficiently disaggregated and homogenous, which minimizes the degree of potential bias in elasticities.
} 
Table 1. Summary Statistics for Fiber Intake Derived from Various Food Categories (Grams per Person per Day)

\begin{tabular}{lccccccccc}
\hline & Bread & Pasta & Tortilla & $\begin{array}{c}\text { Canned } \\
\text { Fruit }\end{array}$ & $\begin{array}{c}\text { Fresh } \\
\text { Fruit }\end{array}$ & $\begin{array}{c}\text { Frozen } \\
\text { Fruit }\end{array}$ & $\begin{array}{c}\text { Canned } \\
\text { Vegetables }\end{array}$ & $\begin{array}{c}\text { Fresh } \\
\text { Vegetables }\end{array}$ & $\begin{array}{c}\text { Frozen } \\
\text { Vegetables }\end{array}$ \\
\hline Mean & 1.15 & 0.40 & 0.33 & 0.34 & 0.93 & 0.23 & 1.06 & 0.95 & 0.62 \\
Std. Dev. & 1.14 & 0.45 & 0.66 & 0.51 & 1.32 & 0.52 & 1.43 & 0.98 & 0.81 \\
Percent Zero & 10.8 & 40.1 & 70.3 & 43.4 & 29.1 & 87.4 & 19.4 & 11.8 & 28.0 \\
$\quad$ Observations & & & & & & & & &
\end{tabular}

Note: This table lists summary statistics conditional on purchasing in that category.

Source: Calculations by the authors. 


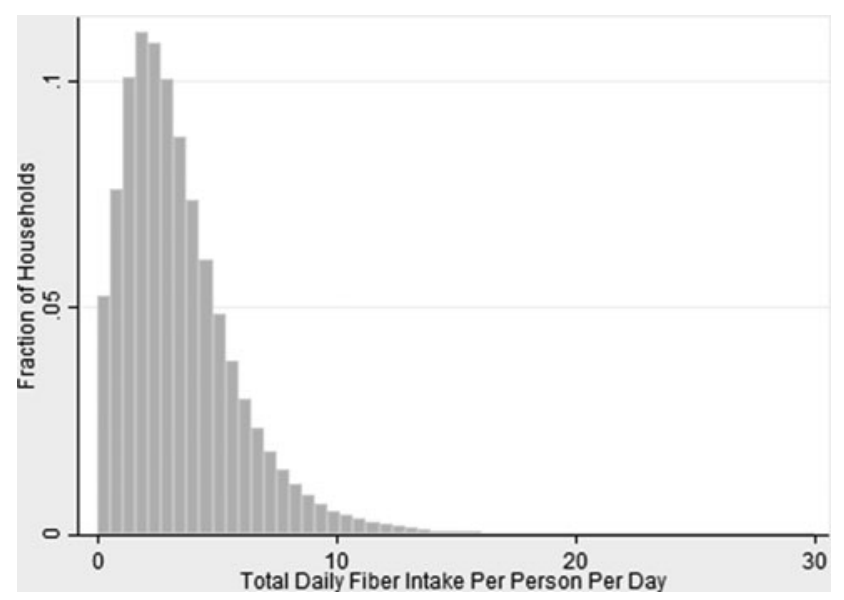

Figure 1. Distribution of Intake of Dietary Fiber per Person from the Nielsen Panel 2004-2014

Note: For the above distribution, the sample average daily dietary fiber intake is 4.38 grams per person. Source: Calculation by the authors.

Table 2. Summary Statistics for Observed and Imputed Prices for Each of the Food Products

\begin{tabular}{lccccccc}
\hline & \multicolumn{3}{c}{ Observed Price $\mathbf{( \$ / 1 0 0 ~ g r a m s ) ~}$} & & \multicolumn{2}{c}{$\begin{array}{c}\text { Imputed Price } \\
\text { (\$/100 grams) }\end{array}$} \\
\cline { 2 - 4 } \cline { 7 - 8 } & Mean & Std. Dev. & NumberObserved & & Mean & Std. Dev. \\
\hline Bread & 0.174 & 0.080 & 388,273 & & 0.176 & 0.076 \\
Pasta & 0.139 & 0.085 & 260,948 & & 0.146 & 0.067 \\
Tortilla & 0.189 & 0.112 & 129,069 & & 0.207 & 0.066 \\
Canned Fruit & 0.126 & 0.059 & 245,509 & & 0.129 & 0.045 \\
Fresh Fruit & 0.181 & 0.154 & 308,410 & & 0.187 & 0.130 \\
Frozen Fruit & 0.291 & 0.109 & 54,798 & & 0.303 & 0.043 \\
Canned Vegetables & 0.111 & 0.102 & 351,108 & & 0.113 & 0.091 \\
Fresh Vegetables & 0.174 & 0.151 & 384,135 & & 0.172 & 0.050 \\
Frozen Vegetables & 0.170 & 0.083 & 313,405 & & 0.169 & 0.070 \\
\hline
\end{tabular}

Note: Imputed prices were calculated with an auxiliary regression that included household income, household size, location, and time as explanatory variables. The number of observed prices is out of a possible 435,424 observations.

Source: Calculations by the authors. 
the means of the observed prices, confirming the consistency of the observed and imputed prices.

A range of standard demographics to uncover the effect of various household characteristics affecting the demand for fiber intake derived from consumption of various foods is exhibited in Table 3. The age variable was constructed to consider only the age of the oldest head of the household. The average age of the head of household in our sample in 2005 in the first quarter is 56 years. ${ }^{9}$ Further, this sample has 5 percent of respondents identified as being of Hispanic origin. Controlling for Hispanic origin (ethnicity) and race is important because such respondents may have different preferences concerning purchases of the respective categories based on sociocultural factors (e.g., tortillas).

We construct an indicator variable for the presence of children in the households. This variable indicates if there is at least one child present in the household. This variable may be important as the presence of children may change the nutritional mix of food purchased. Parents may focus on purchases of a different food mix when children are present in the household.

Household income is included in the set of explanatory variables in the probit models. Nielsen provides only categorical income information. The income variable is constructed as the natural log of the midpoint of the categorical yearly income variable and adjusted for inflation using the Consumer Price Index (CPI). The average real income in our sample is $\$ 27,100$. The poverty dummy variables indicate whether household income is at or below 130 percent of the federal poverty level and whether household income is between 130 percent and 185 percent of the federal poverty level. These variables are calculated using household income and household size. As such, in the second-stage equations, household income and household size do not appear explicitly as explanatory variables in the estimated panel regressions.

The place of residence dummies corresponds to the four major U.S. Census Bureau designated divisions (the Northeast, the Midwest, the South, and the West). These are used to control for possible differences in the characteristics of the food environment. These differences may include the availability of grocery stores and other food outlets or possible geographical differences associated with food tastes and preferences.

\section{Results}

A log-linear functional form is chosen for the second-stage analysis. For brevity, we only report parameter estimates from the second-stage panel regression models (shown in Table 4). ${ }^{10}$ The goodness-of-fit statistics range from 0.029

\footnotetext{
9 Since the sample was constructed to follow only those individuals who participated in the panel for 11 years, the average age of the household head in our sample is higher than that of the U.S. average age of the household head.

10 The results from the first-stage probit models are available from the authors upon request.
} 
Table 3. Summary Statistics Associated with the Set of Explanatory Variables in the Panel Regressions

\begin{tabular}{|c|c|c|}
\hline Variable & $\begin{array}{l}\text { Mean Valueor } \\
\text { Percentage }\end{array}$ & $\begin{array}{l}\text { Std. } \\
\text { Dev. }\end{array}$ \\
\hline \multicolumn{3}{|l|}{ Race } \\
\hline White & $84 \%$ & 0.36 \\
\hline Black & $9 \%$ & 0.29 \\
\hline Asian & $3 \%$ & 0.16 \\
\hline Other & $4 \%$ & 0.19 \\
\hline \multicolumn{3}{|l|}{ Ethnicity } \\
\hline Hispanic origin (any race) & $5 \%$ & 0.21 \\
\hline Age of head of household ${ }^{1}$ & 56.26 & 11.07 \\
\hline \multicolumn{3}{|l|}{ Economic Characteristics } \\
\hline Real household income (\$) & 25,963 & 13,277 \\
\hline Nominal income below $130 \%$ of poverty line & $7 \%$ & 0.26 \\
\hline $\begin{array}{l}\text { Nominal income between } 130 \% \text { and } 185 \% \text { of } \\
\text { poverty line }\end{array}$ & $16 \%$ & 0.16 \\
\hline \multicolumn{3}{|l|}{ Education } \\
\hline Less than HS degree & $1 \%$ & 0.12 \\
\hline HS degree & $20 \%$ & 0.40 \\
\hline Some college & $28 \%$ & 0.45 \\
\hline Bachelor's or higher degree & $50 \%$ & 0.50 \\
\hline \multicolumn{3}{|l|}{ Family Characteristics } \\
\hline At least one child present & $13 \%$ & 0.33 \\
\hline Household Size & 2.08 & 1.10 \\
\hline \multicolumn{3}{|l|}{ Place of residence } \\
\hline Northeast & $17 \%$ & 0.38 \\
\hline Midwest & $26 \%$ & 0.44 \\
\hline South & $35 \%$ & 0.48 \\
\hline West & $22 \%$ & 0.42 \\
\hline
\end{tabular}

${ }^{1}$ Average age at the first quarter of calendar year 2005.

Note: This table lists summary statistics for the explanatory variables in the panel regressions. Except for income, age, and household size, the respective factors are indicator variables. The total number of households is 9,896 .

Source: Calculations by the authors.

(bread) to 0.283 (fresh vegetables). The majority of the estimated own-price and cross-price coefficients (68 out of 81 ) are significantly different from zero at the 0.01 level. The estimated coefficients associated with 130 percent 
Table 4. Parameter Estimates and Associated p-values of the Panel Models

\begin{tabular}{|c|c|c|c|c|c|c|c|c|c|}
\hline & Bread & Pasta & Tortillas & $\begin{array}{c}\text { Canned } \\
\text { Fruit }\end{array}$ & Fresh Fruit & $\begin{array}{c}\text { Frozen } \\
\text { Fruit }\end{array}$ & $\begin{array}{c}\text { Canned } \\
\text { Vegetables }^{\mathrm{a}}\end{array}$ & $\begin{array}{c}\text { Fresh } \\
\text { Vegetables }^{\mathrm{a}}\end{array}$ & $\begin{array}{c}\text { Frozen } \\
\text { Vegetables }^{\mathrm{a}}\end{array}$ \\
\hline Ln Price Bread & $0.382(0.001)$ & $-0.047(0.001)$ & $0.202(0.001)$ & $-0.623(0.001)$ & $-0.301(0.001)$ & $0.113(0.001)$ & $-0.019(0.002)$ & $0.116(0.001)$ & $-0.092(0.001)$ \\
\hline Ln Price Pasta & $0.060(0.001)$ & $0.212(0.001)$ & $0.099(0.001)$ & $0.087(0.001)$ & $-0.025(0.001)$ & $0.048(0.004)$ & $0.165(0.001)$ & $-0.030(0.001)$ & $0.115(0.001)$ \\
\hline Ln Price Tortilla & $0.041(0.001)$ & $0.041(0.001)$ & $-1.279(0.001)$ & $0.091(0.001)$ & $0.039(0.001)$ & $0.069(0.001)$ & $0.111(0.001)$ & $-0.049(0.001)$ & $0.095(0.001)$ \\
\hline $\begin{array}{l}\text { Ln Price Canned } \\
\quad \text { Fruit }\end{array}$ & $-0.015(0.001)$ & $-0.006(0.246)$ & $0.031(0.001)$ & $1.024(0.001)$ & $0.072(0.001)$ & $0.005(0.758)$ & $0.094(0.001)$ & $-0.036(0.001)$ & $0.043(0.001)$ \\
\hline $\begin{array}{l}\text { Ln Price Fresh } \\
\quad \text { Fruit }\end{array}$ & $0.008(0.001)$ & $-0.004(0.131)$ & $0.019(0.001)$ & 0.0 & $(0.001)$ & $0.018)$ & 0.00 & $-0.089(0.001)$ & $(0.768)$ \\
\hline $\begin{array}{l}\text { Ln Price Frozen } \\
\text { Fruit }\end{array}$ & $0.053(0.001)$ & $-0.019(0.069)$ & $0.075(0.001)$ & $0.198(0.001)$ & $0.069(0.001)$ & $0.385(0.001)$ & $0.113(0.001)$ & $0.015(0.094)$ & $0.081(0.001)$ \\
\hline $\begin{array}{l}\text { Ln Price Canned } \\
\text { Vegetables }\end{array}$ & $0.028(0.001)$ & $0.010(0.017)$ & $-0.174(0.003)$ & $0.080(0.001)$ & $0.001(0.855)$ & $0.044(0.001)$ & $-0.460(0.001)$ & $-0.056(0.001)$ & $0.010(0.018)$ \\
\hline $\begin{array}{c}\text { Ln Price Fresh } \\
\text { Vegetables }\end{array}$ & $0.114(0.001)$ & $0.073(0.001)$ & $-0.041(0.001)$ & $0.201(0.001)$ & $0.085(0.001)$ & $0.070(0.001)$ & $0.169(0.001)$ & $-0.965(0.001)$ & $0.181(0.001)$ \\
\hline $\begin{array}{l}\text { Ln Price Frozen } \\
\text { Vegetables }\end{array}$ & $-0.099(0.001)$ & $0.007(0.164)$ & $-0.071(0.001)$ & $-0.013(0.044)$ & $-0.021(0.001)$ & $0.009(0.595)$ & $0.030(0.001)$ & $-0.051(0.001)$ & $-0.144(0.001)$ \\
\hline $\begin{array}{l}\text { 130\% Poverty } \\
\text { Level }\end{array}$ & $0.143(0.001)$ & $(0.001)$ & $-0.225(0.001)$ & 001) & $0.001)$ & $-0.077(0.014)$ & $.001)$ & $-0.176(0.001)$ & $0.001)$ \\
\hline $\begin{array}{l}\text { 185\% Poverty } \\
\text { Level }\end{array}$ & $0.064(0.001)$ & $-0.001(0.902)$ & $-.0118(0.001)$ & $0.010(0.197)$ & $0.201(0.001)$ & $-0.059(0.011)$ & $0.040(0.001)$ & $-0.103(0.001)$ & $0.049(0.001)$ \\
\hline Hispanic & $-0.072(0.001)$ & $-0.139(0.001)$ & $0.457(0.001)$ & $-0.082(0.001)$ & $-0.245(0.001)$ & $-0.108(0.020)$ & $-0.156(0.001)$ & $-0.048(0.004)$ & $0.003(0.882)$ \\
\hline Black & $-0.032(0.059)$ & $-0.007(0.695)$ & $-0.471(0.001)$ & $0.237(0.001)$ & $0.192(0.001)$ & $-0.035(0.428)$ & $0.135(0.001)$ & $-0.407(0.001)$ & $0.048(0.014)$ \\
\hline Asian & $-0.048(0.052)$ & $0.055(0.033)$ & $-0.371(0.001)$ & $0.237(0.106)$ & $-0.101(0.001)$ & $0.012(0.868)$ & $0.022(0.497)$ & $-0.137(0.001)$ & $0.219(0.001)$ \\
\hline Other & $0.002(0.874)$ & $0.029(0.049)$ & $0.049(0.004)$ & $0.074(0.001)$ & $0.057(0.001)$ & $0.026(0.563)$ & $0.021(0.219)$ & $-0.092(0.001)$ & $0.053(0.001)$ \\
\hline Age & $-0.009(0.001)$ & $0.003(0.001)$ & $-0.008(0.001)$ & $-0.016(0.001)$ & $0.009(0.001)$ & $0.007(0.001)$ & $-0.002(0.001)$ & $0.005(0.001)$ & $0.001(0.134)$ \\
\hline Child Present & $-0.510(0.001)$ & $-0.460(0.001)$ & $-0.083(0.001)$ & $-0.663(0.001)$ & $-0.819(0.001)$ & $-0.524(0.001)$ & $-0.521(0.001)$ & $-0.310(0.001)$ & $-0.649(0.001)$ \\
\hline
\end{tabular}

Continued 
Table 4. Continued

\begin{tabular}{|c|c|c|c|c|c|c|c|c|c|}
\hline & Bread & Pasta & Tortillas & $\begin{array}{c}\text { Canned } \\
\text { Fruit }\end{array}$ & Fresh Fruit & $\begin{array}{c}\text { Frozen } \\
\text { Fruit }\end{array}$ & $\begin{array}{c}\text { Canned } \\
\text { Vegetables }^{\mathrm{a}}\end{array}$ & $\begin{array}{c}\text { Fresh } \\
\text { Vegetables }^{\mathrm{a}}\end{array}$ & $\begin{array}{c}\text { Frozen } \\
\text { Vegetables }^{\mathrm{a}}\end{array}$ \\
\hline West & $0.084(0.001)$ & $0.088(0.001)$ & $0.676(0.001)$ & $0.165(0.001)$ & $-0.004(0.836)$ & $0.362(0.001)$ & $0.040(0.022)$ & $-0.136(0.001)$ & $0.189(0.001)$ \\
\hline Midwest & $-0.008(0.553)$ & $0.027(0.028)$ & $-0.105(0.001)$ & $-0.007(0.618)$ & $-0.034(0.036)$ & $0.031(0.279)$ & $-0.043(0.007)$ & $0.056(0.001)$ & $-0.048(0.001)$ \\
\hline Northeast & $-0.010(0.517)$ & $0.179(0.001)$ & $-0.195(0.001)$ & $0.010(0.548)$ & $0.030(0.097)$ & $-0.026(0.420)$ & $0.004(0.840)$ & $0.122(0.001)$ & $0.015(0.381)$ \\
\hline Mills & $-2.793(0.001)$ & $-0.886(0.001)$ & $1.112(0.001)$ & $-2.425(0.001)$ & $-2.865(0.001)$ & $-0.162(0.078)$ & $-2.420(0.001)$ & $0.935(0.001)$ & $-2.552(0.001)$ \\
\hline Constant & $4.499(0.001)$ & $0.749(0.001)$ & $-9.174(0.001)$ & $11.707(0.001)$ & $2.247(0.001)$ & $1.513(0.040)$ & $1.391(0.001)$ & $-8.783(0.001)$ & $1.944(0.001)$ \\
\hline$\sigma_{u}$ & 0.621 & 0.481 & 0.487 & 0.521 & 0.674 & 0.823 & 0.660 & 0.640 & 0.625 \\
\hline$\sigma_{e}$ & 0.658 & 0.676 & 0.703 & 0.832 & 0.830 & 1.011 & 0.941 & 0.727 & 0.801 \\
\hline $\begin{array}{l}\rho \text { (standard } \\
\text { error) }\end{array}$ & 0.471 & 0.336 & 0.324 & 0.282 & 0.397 & 0.399 & 0.329 & 0.437 & 0.378 \\
\hline Wald $\chi^{2}$ & $10,125(0.001)$ & $12,017(0.001)$ & $11,671(0.001)$ & $8,520(0.001)$ & $53,584(0.001)$ & $1,695(0.001)$ & $65,613(0.001)$ & $141,379(0.001)$ & $12,247(0.001)$ \\
\hline$R^{2}$ (overall) & 0.029 & 0.072 & 0.190 & 0.079 & 0.155 & 0.086 & 0.183 & 0.283 & 0.059 \\
\hline
\end{tabular}

Note: This table presents the parameter estimates of the nine panel models. P-values given in parentheses below the coefficients unless otherwise noted. $\sigma_{u}$ represents the overall variance component. $\sigma_{e}$ represents the panel-level variance component. $\rho$ shows the percent contribution to total variance of the panel-level component. A larger $\rho$ means that the panel-level variance component is more important and it is more likely that the panel estimator is different from the pooled estimator. Wald $\chi^{2}$ is a goodness-of-fit test; the null hypothesis is that all of the regression coefficients except the intercept are jointly equal to zero. "Ln" Represents the natural logarithm of the variable.

${ }^{a}$ Category also includes beans.

Source: Calculations by the authors using STATA 14. 
and 185 percent of the poverty level are statistically significant at the 0.01 level, with two exceptions. Moreover, the estimated coefficients in regard to Hispanic origin are statistically significant except for frozen vegetables. In most cases, differences in the level of dietary fiber are evident by race, age of the household head, the presence of children, and by region.

Table 5 presents the conditional marginal effects and Table 6 presents conditional elasticities. The conditional marginal effects and elasticities relate to the changes in the intake of dietary fiber given that the household has a positive intake of dietary fiber in that category. The own-price elasticities are interpreted as the percentage change in the intake of fiber attributed to a 1 percent change in the price of that product containing dietary fiber.

Based on the own-price elasticities, the response to fiber intake associated with price changes is inelastic. All the respective own-price elasticities for fiber are negative, with the exception of fiber derived from frozen fruit (0.174). Omitting frozen fruit, estimates of the conditional own-price elasticities for fiber derived from fruit range from -0.253 for canned fruit to -0.527 for fresh fruit. Estimates of the conditional own-price elasticities for fiber derived from vegetables range from -0.515 for frozen vegetables to -0.971 for canned vegetables. As frozen vegetables are the most inelastic produce item, any subsidy will be least effective at increasing fiber intake if targeting this product. As a reminder on how to interpret these elasticities, using fresh vegetables as an example, a 1 percent increase (decrease) in the price of fresh vegetables results in a 0.815 percent decrease (increase) in the intake of dietary fiber derived from fresh vegetables.

The estimated elasticities are not directly comparable with those found in other studies. The focus in the extant literature was on the quantity demanded of fruits or vegetables and not the intake of dietary fiber derived from the quantity demanded of fruits and vegetables as considered in this study. Nevertheless, it is still informative to compare elasticity estimates for fruit and vegetables, as a change in the consumption of that item will lead to a change in dietary fiber intake. Park et al. (1996) estimated own-price elasticities of -0.34 for fruit and -0.32 for vegetables for low-income households. For low-income households, Dong and Lin (2009) estimated own-price elasticities of -0.52 for fruit and -0.69 for vegetables. Notice that they are all inelastic in demand.

Twenty cross-price elasticities for fiber intake among various products are positive and statistically significant, indicative of substitutes. Nineteen crossprice elasticities are negative and statistically significant, indicative of complements. The majority of the cross-price elasticities (33) are not statistically different from zero. For the cross-price elasticities that are statistically significant, the magnitudes range from -0.081 to 0.146 .

Households below the poverty thresholds have significantly lower fiber intakes in most categories relative to households above the poverty thresholds. Generally, the effect is much stronger for those households below 
Table 5. Conditional Marginal Effects of the Panel Models

\begin{tabular}{|c|c|c|c|c|c|c|c|c|c|}
\hline & Bread & Pasta & Tortillas & $\begin{array}{c}\text { Canned } \\
\text { Fruit }\end{array}$ & $\begin{array}{l}\text { Fresh } \\
\text { Fruit }\end{array}$ & $\begin{array}{c}\text { Frozen } \\
\text { Fruit }\end{array}$ & $\begin{array}{c}\text { Canned } \\
\text { Vegetables }^{\mathrm{d}}\end{array}$ & $\begin{array}{c}\text { Fresh } \\
\text { Vegetables }^{\mathrm{d}}\end{array}$ & $\begin{array}{c}\text { Frozen } \\
\text { Vegetables }^{\mathrm{d}}\end{array}$ \\
\hline $\begin{array}{l}\text { Below 130\% } \\
\text { Poverty } \\
\text { Level }\end{array}$ & -0.072 & -0.060 & -0.018 & -0.081 & -0.089 & -0.101 & -0.075 & -0.091 & -0.074 \\
\hline $\begin{array}{l}130 \% \text { to } 185 \% \\
\text { Poverty } \\
\text { Level }\end{array}$ & -0.041 & -0.051 & -0.028 & -0.034 & -0.070 & -0.071 & -0.048 & -0.063 & -0.066 \\
\hline Hispanic $^{\text {a }}$ & -0.070 & -0.119 & 0.234 & -0.171 & -0.049 & -0.101 & -0.031 & -0.064 & -0.091 \\
\hline Black $^{\text {b }}$ & -0.101 & -0.133 & -0.085 & -0.071 & -0.101 & -0.063 & -0.111 & -0.321 & 0.106 \\
\hline Asian ${ }^{b}$ & -0.235 & -0.040 & -0.148 & -0.273 & 0.078 & -0.007 & -0.258 & -0.125 & -0.142 \\
\hline Other ${ }^{b}$ & -0.026 & -0.026 & 0.071 & -0.041 & -0.046 & 0.020 & -0.064 & -0.073 & -0.017 \\
\hline $\begin{array}{l}\text { Age of oldest } \\
\text { head of } \\
\text { household }\end{array}$ & -0.006 & 0.001 & 0.004 & 0.001 & 0.020 & 0.008 & 0.004 & 0.003 & -0.001 \\
\hline Child present & -0.197 & -0.262 & -0.343 & -0.367 & -0.337 & -0.508 & -0.335 & -0.375 & -0.245 \\
\hline West $^{c}$ & 0.070 & 0.074 & 0.226 & 0.120 & 0.012 & 0.370 & -0.121 & -0.109 & -0.075 \\
\hline Midwest $^{c}$ & 0.016 & 0.072 & -0.138 & 0.071 & 0.136 & 0.036 & -0.140 & 0.044 & -0.67 \\
\hline Northeast ${ }^{\mathrm{c}}$ & 0.061 & 0.315 & -0.127 & 0.057 & 0.055 & -0.031 & -0.140 & 0.117 & 0.031 \\
\hline
\end{tabular}

Note: This table presents the estimated conditional marginal effects of the panel models. The use of conditional implies that the marginal effect is calculated for non-zero purchases. Bold represents significance at the $5 \%$ level (p-value less than 0.05 ).

a The base category is non-Hispanic origin.

b The base category is White.

${ }^{c}$ The base category is South region.

${ }^{\mathrm{d}}$ Category also includes beans.

Source: Calculations by the authors. 
Table 6. Conditional Own-Price and Cross-Price Elasticities of the Derived Demand for Fiber Generated from the Panel Models

\begin{tabular}{|c|c|c|c|c|c|c|c|c|c|}
\hline & Bread & Pasta & Tortilla & $\begin{array}{c}\text { Canned } \\
\text { Fruit }\end{array}$ & $\begin{array}{l}\text { Fresh } \\
\text { Fruit }\end{array}$ & $\begin{array}{c}\text { Frozen } \\
\text { Fruit }\end{array}$ & $\begin{array}{c}\text { Canned } \\
\text { Vegetables }^{\mathrm{a}}\end{array}$ & $\begin{array}{c}\text { Fresh } \\
\text { Vegetables }^{\mathrm{a}}\end{array}$ & $\begin{array}{c}\text { Frozen } \\
\text { Vegetables }^{\mathrm{a}}\end{array}$ \\
\hline Bread & -0.134 & 0.038 & 0.066 & -0.007 & 0.092 & 0.146 & 0.064 & 0.056 & 0.036 \\
\hline Pasta & -0.043 & -0.297 & 0.055 & -0.007 & 0.031 & 0.062 & 0.004 & -0.007 & 0.007 \\
\hline Tortilla & -0.032 & 0.005 & -0.366 & -0.007 & 0.022 & 0.071 & -0.027 & -0.024 & -0.004 \\
\hline Canned Fruit & -0.036 & 0.002 & 0.013 & -0.253 & -0.005 & 0.001 & -0.023 & -0.012 & -0.020 \\
\hline Fresh Fruit & -0.022 & -0.014 & -0.002 & -0.054 & -0.527 & -0.025 & -0.048 & -0.051 & -0.026 \\
\hline Frozen Fruit & -0.008 & 0.051 & 0.032 & 0.070 & 0.093 & 0.174 & 0.144 & 0.034 & 0.074 \\
\hline $\begin{array}{l}\text { Canned } \\
\text { Vegetables }\end{array}$ & -0.035 & -0.017 & -0.007 & -0.061 & -0.014 & 0.043 & -0.971 & -0.039 & -0.004 \\
\hline $\begin{array}{l}\text { Fresh } \\
\quad \text { Vegetables }\end{array}$ & -0.027 & -0.013 & 0.016 & -0.030 & 0.007 & 0.072 & -0.034 & -0.815 & -0.013 \\
\hline $\begin{array}{l}\text { Frozen } \\
\text { Vegetables }\end{array}$ & -0.026 & -0.010 & -0.003 & -0.081 & 0.010 & 0.010 & -0.002 & -0.030 & -0.515 \\
\hline
\end{tabular}

Note: This table presents the estimated conditional elasticities of the panel models. The use of the term conditional implies that the elasticity is calculated for non-zero purchases. Bold represents significance at the 5 percent level ( $p$-value less than 0.05 ).

${ }^{a}$ Category also includes beans.

Source: Calculations by the authors. 
130 percent of the poverty level than those households between 130 percent and 185 percent of the poverty level. The largest effects are for fiber derived from bread, canned fruit, fresh fruit, and frozen fruit.

We find that the presence of children in the household is associated with lower per person fiber intake across all food categories. Further refinement by including classifications for different ages of children may reveal other effects as children require less fiber than adults.

Households with older household heads have more fiber intake from fresh fruit, frozen fruit, and canned vegetables relative to households with younger household heads. The reverse is true for dietary fiber from bread. Additionally, regional differences in fiber intake are evident. Households located in the Northeast have higher intakes of dietary fiber from bread, pasta, canned fruit, fresh fruit, and fresh vegetables relative to households located in the South. The reverse is the case for intake of fiber from tortillas and canned vegetables.

Households located in the Midwest have higher intakes of fiber from pasta, canned fruit, fresh fruit, frozen fruit, and fresh vegetables relative to households located in the South. The reverse is true in regard to dietary fiber intake derived from purchases of tortillas, canned vegetables, and frozen vegetables. Households residing in the West have higher intakes of dietary fiber from purchases of bread, pasta, tortillas, canned fruit, and frozen fruit relative to households residing in the South but lower intakes of dietary fiber from purchases of canned vegetable, fresh vegetables, and frozen vegetables.

Hispanic households have lower intakes of dietary fiber from purchases of bread, pasta, canned fruit, frozen fruit, fresh vegetables, and frozen vegetables relative to non-Hispanic households. Hispanic households have a higher intake of dietary fiber derived from purchases of tortillas. Black households have lower intakes of dietary fiber on a per person basis derived from purchases of all food categories excluding frozen vegetables relative to white households. Similarly, Asian households have lower intake of dietary fiber derived from purchases across all categories.

Table 7 shows the effects of a 20 percent price decrease of respective products due to a subsidy, which would reduce the price consumers pay, applied to the different scenarios. Note that we have considered a 100 percent pass-through of subsidy effects (price reduction) to consumers in this study. In other words, producers face a flat (perfectly elastic) supply function, making the full effect of the subsidy available for consumers. The calculations use the conditional elasticities discussed previously. The conditional elasticities have policy relevance, as we believe it would be easier to encourage those already consuming dietary fiber to consume more than it would be to encourage an individual not consuming dietary fiber to start consuming it. We acknowledge, however, that the total effect of any subsidy that is counting on inducement to purchase and incentivizing increases in dietary fiber conditional on food purchases may be different. 
Table 7. Percent Change in Grams/Day Fiber Intake from a Proposed 20\% Price Decrease due to a Subsidy

\begin{tabular}{|c|c|c|c|c|c|c|c|c|c|c|}
\hline & Bread & Pasta & Tortilla & $\begin{array}{c}\text { Canned } \\
\text { Fruit }\end{array}$ & $\begin{array}{c}\text { Fresh } \\
\text { Fruit }\end{array}$ & $\begin{array}{c}\text { Frozen } \\
\text { Fruit }\end{array}$ & $\begin{array}{c}\text { Canned } \\
\text { Vegetables }\end{array}$ & $\begin{array}{c}\text { Fresh } \\
\text { Vegetables }\end{array}$ & $\begin{array}{c}\text { Frozen } \\
\text { Vegetables }\end{array}$ & $\begin{array}{c}\text { Total } \\
\text { Percent } \\
\text { Change }\end{array}$ \\
\hline Scenario 1 & -7.74 & -1.8 & -0.62 & 6.24 & 14.62 & -11.78 & 20.92 & 16.26 & 12.16 & 9.41 \\
\hline Scenario 2 & -1.14 & 0.06 & 0.68 & 5.52 & 2.04 & -4.28 & 20.64 & 1.28 & 1.66 & 4.73 \\
\hline Scenario 3 & -2.96 & -0.48 & 0.04 & 0.34 & 11.56 & -2.54 & 1.06 & 16.16 & 0.4 & 4.78 \\
\hline Baseline grams/day & 0.90 & 0.22 & 0.09 & 0.16 & 0.75 & 0.04 & 0.82 & 0.83 & 0.42 & \\
\hline
\end{tabular}

Note: The baseline grams per day is the average of last 4 quarters of the per person fiber intake in the respective category. This baseline amount is increased or decreased by the corresponding conditional own and cross price elasticities to find the percent change for each category. The total percent change is the difference from the total baseline amount of 4.23 grams per day and the amount after the subsidy is applied.

Scenario 1 is a subsidy that changes the price by 20 percent applied to all fruit and vegetables.

Scenario 2 is this subsidy applied to only canned fruit and vegetables.

Scenario 3 is the subsidy applied to only fresh fruit and vegetables.

Source: Calculations by the authors. 
In scenario 1, a 20 percent price decrease due to a subsidy applied to all categories of fruits and vegetables would result in an increase in the average per person intake of fiber per day by 9.4 percent. To provide perspective, the weighted average of all fruits and vegetables is $\$ 0.158 / 100$ grams, hence this 20 percent price decrease due to a subsidy is tantamount to $\$ 0.032 / 100$ grams of all fruits and vegetables per household. In scenario 2, where a subsidy is applied to only canned products, the result is a 4.7 percent increase. In scenario 3, where a subsidy is applied to only fresh products, the result is a 4.8 percent increase. Not surprisingly, a subsidy targeting all categories of fruits and vegetables yields the highest percent change in the intake of dietary fiber. That said, a 20 percent price decrease due to a subsidy applied to all categories of fruits and vegetables would raise the average dietary fiber intake in our sample from 4.38 grams per person to 4.79 grams per person, a gain of only 0.41 grams per person. Given the multifaceted causes of consumption decisions, one should not expect a price subsidy alone to close the entire gap to meet the recommended intake of 25 grams per person according to the 2015-2020 Dietary Guidelines for Americans.

As exhibited in Table 7, the effects of the 20 percent price decrease due to a subsidy are not very effective in the attempt to meet the dietary fiber intake guideline. Therefore, it would be informative to determine the level of subsidy required to meet the daily fiber guideline assuming that a subsidy is the only available policy instrument. Also, assuming the elasticities do not change over the range of a subsidy and given a target of 25 grams per day, we can determine the magnitude of this price decrease due to subsidy. That said, as stated previously, in our sample only 4.38 grams of dietary fiber intake was noted on average per person per day, a far cry from the recommended 25 grams per person per day. Given this caveat, a price decrease due to a subsidy of 920 percent applied to all types of fruits and vegetables, ceteris paribus, would be necessary to achieve 25 grams per day, the recommended dietary fiber amount. Without question, this level of subsidy (or price decrease) is not realistic. ${ }^{11}$ Nevertheless, this finding substantiates the point that a subsidy alone likely would not be feasible in getting consumers to actually meet the dietary fiber intake guideline.

\section{Conclusions, Implications, and Limitations}

A panel regression concerning fiber intake obtained from purchases of bread, pasta, tortilla, fresh fruit, fresh vegetables and beans, frozen fruit, frozen

\footnotetext{
11 Per reviewers' request, we repeated this analysis using an average intake of 16 grams/day as the starting level. This is based on the 15.5 grams/day to 16.1 grams/ day based on King, Mainous, and Lambourne (2012). We divide the 16 grams/day into the nine categories while maintaining similar proportions to our data. This analysis requires a subsidy of around $106 \%$, cetris paribus, to reach the recommended 25 grams per person per day fiber requirement.
} 
vegetables and beans, canned fruit, and canned vegetables and beans was conducted. We sought to uncover socioeconomic and demographic factors on the per person intake of dietary fiber in the United States. Furthermore, an inquiry into a subsidy that changed price by 20 percent on the aforementioned food categories to encourage the intake of fiber was conducted.

Estimates of the conditional own-price elasticities for fiber derived from fruit ranged from -0.25 for canned fruit to -0.53 for fresh fruit. Estimates of the conditional own-price elasticities for fiber derived from vegetables ranged from -0.52 for frozen vegetables to -0.97 for canned vegetables. Households whose incomes were below 130 percent of the poverty level and those between 130 percent and 185 percent of the poverty level purchased less fiber per person relative to households whose incomes were above these poverty levels.

Concerning socioeconomic and demographic variables, the presence of children in the household was associated with lower per person fiber intake across all food categories. Households with older household heads had higher intakes of dietary fiber from pasta, tortillas, fresh fruit, frozen fruit, canned vegetables, and fresh vegetables relative to households with younger household heads. Households located in the Northeast had higher intakes of dietary fiber from bread, pasta, canned fruit, fresh fruit, and fresh vegetables relative to households located in the South. Hispanic households had lower intakes of dietary fiber from purchases across all categories except tortillas relative to non-Hispanic households. Black households had lower intakes of dietary fiber on a per person basis derived from purchases of all food categories excluding frozen vegetables relative to white households.

A proposed subsidy that changed price by 20 percent applied to all categories of fruits and vegetables would result in raising the average per person intake of fiber per day by 9.4 percent, a gain of only 0.41 grams per person on average. Thus, subsidies associated with fruits and vegetables alone likely would not be feasible to encourage consumers to meet the dietary fiber guideline. Other instruments to raise dietary fiber intake include policy or voluntary persuasion at the manufacturer level (e.g., reformulation to whole-grain bread), agriculture (more fruits and vegetables), and food service guidelines (school meal standards).

Concerning limitations, the use of the Nielsen panel of households over the 11-year period from 2004 through 2014 prevents the generalization of results to all households. ${ }^{12}$ Further, the Nielsen data may not necessarily be representative of the population in regard to households of Hispanic origin, the age of the head of household, or the percentage of households with children.

Fiber intake derived from eating away from home is not captured in this dataset. That said, 76 percent of the dietary fiber is provided by foods

\footnotetext{
12 Einay, Leibtag, and Nevo (2010) have formulated a method to help correct for possible entry errors in the dataset.
} 
consumed at home, with the remaining 24 percent provided by foods consumed away from home (Economic Research Service 2014). Importantly, random weight fruit and vegetable purchases were excluded, leading to the understatement of dietary fiber intake. Finally, this analysis includes only intake of dietary fiber from nine food sources. Further research should expand the coverage of foods in ascertaining appropriate intakes of dietary fiber.

Further, this dataset does not provide time spent preparing food and only includes food purchases. The need to account for time may be important in purchase decisions (Aguiar and Hurst 2005; Senia et al. 2017). Despite this potential limitation, the food items purchased in our analysis were typically ready to eat and needed little preparation time. Moreover, one must be careful to differentiate between foods that are purchased and foods that are consumed. Purchase and consumption are not synonymous. No information, however, is provided on food waste.

\section{Financial Disclosure}

This research received no specific grant from any funding agency, or commercial or not-for-profit sectors.

\section{Conflicts of Interest}

None.

\section{Transparency and Openness Promotion Statement}

We have used the Nielsen Homescan Panel data from 2004 through 2014 in the analysis. According to the data sharing agreement with the James M. Kilts Center for Marketing, The University of Chicago Booth School of Business, we are not in a position to share data directly with anyone who wishes to use the data to replicate the work. However, according to the data agreement clause, this data are accessible to independent researchers who wish to conduct this analysis; they must contact the James M. Kilts Center for Marketing directly at nielsen@chicagobooth.edu to discuss getting access to this data. A copy of the programs used to create the final results is available upon request.

\section{References}

Aguiar, M., and E. Hurst. 2005. "Consumption Versus Expenditure." Journal of Political Economy 113(5): 919-948.

Alviola, P.A., and O. Capps Jr. 2010. "Household Demand Analysis of Organic and Conventional Fluid Milk in the United States Based on the 2004 Nielsen Homescan Panel." Agribusiness: An International Journal 26(3): 369-388. 
Anderson, J.W., P. Baird, R.H. Davis, S. Ferreri, M. Knudtson, A. Koraym, V. Waters, and C.L Williams. 2009. "Health Benefits of Dietary Fiber." Nutrition 67(4): 188-205.

Capps, O. Jr., R. Tsai, R. Kirby, and G. Williams. 1994. "A Comparison of Demand for Meat Products in the Pacific Rim Region." Journal of Agricultural and Applied Economics 19 (1): 210-224.

Dettmann, R.L., and C. Dimitri. 2009. "Who's Buying Organic Vegetables? Demographic Characteristics of US Consumers." Journal of Food Products Marketing, 16(1):79-91.

Dharmasena, S. and O. Capps Jr. 2014. "Unraveling Demand for Dairy-Alternative Beverages in the United States: The Case of Soymilk." Agricultural and Resource Economics Review 43 (1): $140-157$

Dharmasena, S., O. Capps Jr., and A. Clauson. 2011. "Ascertaining the Impact of 2000 USDA Dietary Guidelines for Americans on the Intake of Calories, Caffeine, Calcium and Vitamin C from at-home Consumption of Nonalcoholic Beverages." Journal of Agricultural and Applied Economics, 43(1): 13-27

Dong, D., and B.H. Lin. 2009. Fruit and Vegetable Consumption by Low-Income Americans: Would a Price Reduction Make a Difference? Economic Research Report Number 70, January, Economic Research Service, U.S. Department of Agriculture, Washington, DC.

Economic Research Service. 2014. Average Daily Intake of Nutrients by Food Source and Demographic Characteristics, 2007-10. Available at http://www.ers.usda.gov/dataproducts/food-consumption-and-nutrient-intakes.aspx (accessed July 2018).

- 2015. Nutrients (Food Energy, Nutrients, and Dietary Components). Available at http://www.ers.usda.gov/data-products/food-availability-(per-capita)-data-system/.aspx (accessed July 2018).

Einav, L., E. Leibtag, and A. Nevo. 2010. "Recording Discrepancies in Nielsen Homescan Data: Are They Present and do They Matter?" Quantitative Marketing in Economics 8(2): 207-239.

Fung, T.T., F.B. Hu, M.A. Pereira, S. Liu, M.J. Stampfer, G.A. Colditz, and W.C. Willett. 2002. "Whole-Grain Intake and the Risk of Type 2 Diabetes: A Prospective Study in Men." American Journal of Clinical Nutrition 76: 535-540.

Heckman, J. 1979. "Sample Selection Bias as a Specification Error." Econometrica 47:153-161.

Hoy, M.K., and J.D. Goldman. 2010. Fiber intake of the U.S. population: What we eat in America, NHANES 2009-2010. Data Brief No. 12, September, Food Surveys Research Group, U.S. Department of Agriculture, Washington, DC.

Kennedy, P. 2003. A Guide to Econometrics. Cambridge, MA: MIT Press.

King, D.E., A.G. Mainous, and C.A. Lambourne. 2012. "Trends in Dietary Fiber Intake in the United States." Journal of the Academy of Nutrition and Dietetics 112(5): 642-648.

Klerman, J.A., S. Bartlett, P. Wilde, and L.E.W. Olsho. 2014. "The Short-Run Impact of the Healthy Incentives Pilot Program on Fruit and Vegetable Intake." American Journal of Agricultural Economics 96(5): 1372-1382.

Klerman, J.A., A.M. Collings, and L.E.W. Olsho. 2017. "Improving Nutrition by Limiting Choice in the Supplemental Nutrition Assistance Program." American Journal of Preventive Medicine 52(2): S171-S178.

Krishnan, S., L. Rosenberg, M. Singer, F.B. Hu, L. Djoussé, L.A. Cupples, and J.R. Palmer. 2007. "Glycemic Index, Glycemic Load, and Cereal Fiber Intake and Risk of Type 2 Diabetes in U. S. Black Women." Archives of Internal Medicine 167: 2304-2309.

Kyureghian, G., O. Capps Jr., and R.M. Nayga Jr. 2011. "A Missing Variable Imputation Methodology with an Empirical Application." Advances in Econometrics, 27: 313.

Lin, B.H., S.T. Yen, D. Dong, and A.M. Smallwood. 2010. "Economic Incentives for Dietary Improvement Among Food Stamp Recipients." Contemporary Economic Policy 28: 524-536.

Liu, S., W.C. Willett, M.J. Stampfer, F.B. Hu, L. Sampson, C.H. Hennekens, and J.E. Manson. 2000. "A Prospective Study of Dietary Glycemic Load, Carbohydrate Intake, and Risk of Coronary Heart Disease in U.S. Women." American Journal of Clinical Nutrition 71: 1455-146. 
Mancino, L., and F. Kuchler. 2012. "Demand for Whole-Grain Bread Before and After the Release of the Dietary Guidelines." Applied Economic Perspectives and Policy 34(1): 76-101.

Mancino, L., F. Kuchler, and E. Leibtag. 2008. "Getting Consumers to Eat More Whole-Grains: The Role of Policy, Information, and Manufacturers." Food Policy 33(6): 489-496.

McKeown, N.M., J.B. Meigs, S. Liu, P.W. Wilson, and P.F. Jacques. 2002. "Whole-Grain Intake is Favorably Associated with Metabolic Risk Factors for Type 2 Diabetes and Cardiovascular Disease in the Framingham Offspring Study." American Journal of Clinical Nutrition 76(2): 390-398.

Michels, K.B., B.R. Bloom, P. Riccardi, B.A. Rosner, and W.C. Willett. 2008. "A Study of the Importance of Education and Cost Incentives on Individual Food Choices at the Harvard School of Public Health Cafeteria." Journal of the American College of Nutrition 27(1): 6-11.

Miguel, H.O., and D. Dong. 2012. "Assessing U.S. Household Purchase Dynamics for Dietary Fiber." Selected paper presented at 2012 annual meetings of the Agricultural and Applied Economics Association, Seattle, Washington.

Nielsen 2018. "Nielsen Homescan Panel," Kilts Center for Marketing Data Center at The University of Chicago Booth School of Business.

Park, J., R. Holcomb, K. Raper, and O. Capps Jr. 1996. "A Demand System Analysis of Food Commodities by U.S. Households Segmented by Income." American Journal of Agricultural Economics 78(2): 290-300.

Pereira, M.A., E. O’Reilly, K. Augustsson, G.E. Fraser, U. Goldbourt, B.L. Heitmann, G. Hallmans, P. Knekt, S. Liu, P. Pietinen, D. Spiegelman, J. Stevens, J. Virtam, W.C. Willett, and A. Ascherio. 2004. "Dietary Fiber and Risk of Coronary Heart Disease: A Pooled Analysis of Cohort Studies." Archives of Internal Medicine 164(4): 370-376.

Piernas, C., M.A. Mendez, S.W. Ng, P. Gordon-Larsen, and B.M. Popkin, 2013. "Low-Calorie-and Calorie-Sweetened Beverages: Diet Quality, Food Intake, and Purchase Patterns of US Household Consumers." The American Journal of Clinical Nutrition, 99(3): 567-577.

Rimm, E.B., A. Ascherio, E. Giovannucci, D. Spiegelman, M.J. Stamfer, and W.C. Willett. 1996. "Vegetable, Fruit, and Cereal Fiber Intake and Risk of Coronary Heart Disease Among Men." Journal of the American Medical Association 275: 447-451.

Saha, A., O. Capps Jr., and P.J. Byrne. 1997. "Calculating Marginal Effects in DichotomousContinuous Models." Applied Economics Letters 4: 181-185.

Senia, M.C., H.H. Jensen, and O. Zhylyevskyy. 2017. "Time in Eating and Food Preparation Among Single Adults." Review of Economics of the Household. 15(2):399-432.

STATA (software). 2015. Stata 14 Base Reference Manual. College Station, TX: Stata Press.

U.S. Department of Health and Human Services and U.S. Department of Agriculture (HHS and USDA). 2005. Dietary Guidelines for Americans, 2005. 6th Edition, Washington, DC: U.S. Government Printing Office, January.

— 2010. Dietary Guidelines for Americans, 2010. 7th Edition, Washington, DC: U.S. Government Printing Office, December.

— 2015. 2015-2020 Dietary Guidelines for Americans. 8th Edition. Available at http:// health.gov/dietaryguidelines/2015/guidelines/ (accessed July 2018).

Wilde, P., J.A. Klerman, L.E.W. Olsho, and S. Bartlett. 2016. "Explaining the Impact of USDA's Healthy Incentives Pilot on Different Spending Outcomes." Applied Economic Perspectives and Policy 38(4): 655-672.

Zhen, C., E.A. Finkelstein, J.M. Nonnemaker, S.A. Karns, and J.E. Todd. 2013. "Predicting the Effects of Sugar-Sweetened Beverage Taxes on Food and Beverage Demand in a Large Demand System." American Journal of Agricultural Economics, 96(1): 1-25. 